\title{
Calcareous spherules produced by intracellular symbiotic bacteria protect the sponge Hemimycale columella from predation better than secondary metabolites
}

\author{
Leire Garate, Andrea Blanquer, María-J. Uriz* \\ Centre d'Estudis Avançats de Blanes (CEAB-CSIC), Access Cala Sant Francesc 14, 17300 Blanes (Girona), Spain
}

\begin{abstract}
Benthic sessile organisms in general, and sponges in particular, have developed an array of defense mechanisms to survive in crowded, resource and/or space-limited environments. Indeed, various defense mechanisms may converge in sponges to accomplish a defensive function in an additive or synergetic way, or to operate at different times during the sponge's life cycle. Moreover, sponges harbor highly diverse microbial communities that contribute in several ways to the host's success. Although some symbiotic bacteria produce chemical compounds that protect the sponge from predation, the possible deterrent function exerted by the calcareous coat of a sponge's endosymbiotic bacterium has not, to date, been explored. Hemimycale columella is an Atlanto-Mediterranean sponge, which produces bioactive metabolites and has been reported to host an intracellular bacterium with a calcite envelope. Calcibacteria accumulate in high densities at the sponge periphery, forming a kind of sub-ectosomal cortex. They have been suggested to provide the sponge with several benefits, one of which is protection from predators. In this study, we assess the relative contribution of the endosymbiotic calcibacteria and bioactive compounds produced by $H$. columella to defend the sponge against sympatric predators. Deterrence experiments have revealed that the sponge combines $>1$ defense mechanism to dissuade a large array of potential predators; this represents an example of the evolutionary fixation of redundant mechanisms of defense. The chemicals deterred Paracentrotus lividus, Chromis chromis, Oblada melanura, and Diplodus vulgaris, but not Parablennius incognitus and Coris julis, while the spherules of the symbiotic calcibacteria significantly deterred all predators assayed.
\end{abstract}

KEY WORDS: Chemical defenses - Calcifying bacteria $\cdot$ Sponge endosymbiosis $\cdot$ Sponge deterrence $\cdot$ Calcite spherules $\cdot$ Hemimycale columella $\cdot$ Atlanto-Mediterranean

\section{INTRODUCTION}

Species coexistence, which determines the biodiversity of a given ecosystem, is the result of several long discussed, biological, and ecological mechanisms such as environmental variation (Chesson \& Warner 1981), resource and/or niche partitioning (Chesson 2000), and species-specific interactions, which involve species-specific mechanisms of defense (Buss 1976).
Benthic sessile organisms in general, and sponges in particular, have developed an array of defense mechanisms to survive in crowded, resource and/or space-limited environments. Structural materials, such as external and internal skeletons, dermal spines, or protruding spicules serve as defense for benthic invertebrates and fish by protecting their soft tissues and, thus, dissuading most potential benthic predators. Conversely, bioactive chemicals usually act in a 
less generalist way. Some chemicals may deter one or more species from predation on the producer organism while they may not deter others (Becerro et al. 2003). On the whole, chemical defenses have been reported to significantly contribute to the structure of sponge assemblages on coral reefs (Loh \& Pawlik 2014) and have been proposed to favor complex interaction networks, which are responsible for increasing species coexistence and thus biodiversity (Buss 1976, Loh \& Pawlik 2014). On the other hand, mineral skeletons would only improve species persistence by offering general protection to the organisms (Uriz et al. 2003).

Sponges are a notable component of the marine benthos, where they share habitat with an array of potential predators (McClintock et al. 1994, Wulff 2000, Santos et al. 2002, Leon \& Bjorndal 2002, Knowlton \& Highsmith 2005). Thus, besides competing for growth space with other benthic organisms such as algae, corals, ascidians, and bryozoans, sponges must also handle predation. Indeed, sponge survival has required the development of several defense mechanisms, which comprise the production of chemical compounds and structural elements (Uriz et al. 2003, Jones et al. 2005), along with cryptic growth habits (Bertolino et al. 2013).

Many of the bioactive compounds produced by sponges with antimitotic, cytotoxic, antibacterial, and/or antitumor activities (Amade et al. 1987, Uriz et al. 1992, Becerro et al. 1994, Monks et al. 2002, Sipkema et al. 2005, Blunt et al. 2009, Hardoim \& Costa 2014) inhibit the settlement of foreign larvae in the proximity of the sponge (Martin \& Uriz 1993, Becerro et al. 1997a, 2003, De Caralt et al. 2013) or deter predation (Uriz et al. 1996, Ribeiro et al. 2010, Arias et al. 2011). Spicules have also been reported to dissuade sponge predators to some extent (Burns \& Ilan 2003, Hill et al. 2005, Jones et al. 2005, but see Chanas \& Pawlik 1995). Thus, various defense mechanisms converge in most sponges to accomplish a defensive function in an additive or synergetic way, or to operate at different times during the sponge's life cycle (Uriz et al. 1996). However, the opposite is also true: multiple functions have also been reported for a sole defense mechanism (Thacker et al. 1998, Becerro et al. 1997a). Furthermore, the efficiency of a deterrent mechanism can vary according to the predator (Becerro et al. 2003), which makes the results of deterrence assays difficult to generalize.

To add to the complexity of defense mechanisms, sponges harbor highly diverse microbial communities (e.g. Blanquer et al. 2013), which form stable symbiotic associations and contribute in several ways to the host's success (Taylor et al. 2007, Thacker \&
Freeman 2012). For instance, some sponge symbiotic bacteria produce chemical compounds that protect the sponge from predation (Thacker et al. 1998, Haber et al. 2011, Esteves et al. 2013). However, the possible deterrent function of an endosymbiotic bacterium, other than that mediated by bioactive chemicals, has not been explored to date.

Hemimycale columella (Bowerbank, 1874) is a common encrusting demosponge (Order Poecilosclerida) widespread in the Mediterranean and North Atlantic sublittorals. The species, which has a reduced ectosomal skeleton (Van Soest 2002), produces chemical compounds with cytotoxic and antimitotic activities (Uriz et al. 1992, Becerro et al. 1997a) that might deter its potential predators. However, H. columella has also been reported to host an intracellular bacterium with calcifying abilities (Uriz et al. 2012). Bacteria that are surrounded by a $100 \mathrm{~nm}$ thick calcite envelope have been detected by catalyzed reporter deposition fluorescence in situ hybridization (CARD-FISH) and transmission electron microscopy (TEM) in high numbers within a particular sponge cell type called calcibacteriocyte (Uriz et al. 2012). Thousands of bacteriumproduced calcite spherules are accumulated at the sponge periphery, forming a kind of sub-ectosomal cortex that mimics a rudimentary exoskeleton (Uriz et al. 2012). It has been proposed that this unusual, intimate symbiosis, which is vertically transmitted to progeny and constantly present in all populations of $H$. columella examined along the western Mediterranean sublittoral zone, purportedly provides the sponge with several benefits, among which protection from predators has been highlighted (Uriz et al. 2012).

In this study, we aimed to assess the relative contributions of the calcite spherules of endosymbiotic calcibacteria and the bioactive compounds produced by $H$. columella to sponge defense, and whether the combination of secondary metabolites and the calcibacterial calcareous envelope exerted a synergetic effect in deterring potential predators from feeding on the sponge. With this aim, we conducted several deterrence experiments, both in the laboratory and in the sponge's habitat, with an array of sympatric potential predators (echinoderms and fishes).

\section{MATERIALS AND METHODS}

\section{Sampling, sponge identification, and location of bacteria}

Between 8 and 12 individuals of Hemimycale columella were randomly collected from the Blanes lit- 
toral zone, NW Mediterranean $\left(41^{\circ} 40.12^{\prime} \mathrm{N}, 2^{\circ} 47.10^{\prime} \mathrm{E}\right)$, in each of 3 sampling dives, to prepare the artificial food used in the experiments. The species was taxonomically identified by phenotypic characters, such as external morphology (i.e. thick encrusting shape, presence of characteristic rounded pore sieves with elevated rims, pale orange to pink color, and spicule shape [strongyles to styles], size [320 to $461 \mu \mathrm{m} \times 2.5$ to $7.5 \mu \mathrm{m}$ ), and plumose arrangement [Van Soest 2002]). The sponge samples were taken to the laboratory in hermetic, seawater-filled bowls, blended, and weighed after removing foreign material under a stereo-microscope. Half of the sponge mix was frozen for obtaining the crude chemical extract (potential chemical defenses), while the other half was used to isolate the calcite spherules, which represented the purported physical defenses.

Light-microscope pictures were obtained by using forceps to break up recently collected sponges and by direct observation of the resulting disaggregated cells though a Zeiss (Axioplan) microscope connected to a Jenoptik/Jena (ProgRes C10 plus) digital camera.

For TEM, samples of ca. $2 \mathrm{~mm}^{3}$ in size were fixed in $1 \% \mathrm{OsO}_{4}$ and $2 \%$ glutaraldehyde (1:3) in $0.45 \mathrm{M}$ sodium acetate buffer ( $\mathrm{pH}$ 6.4) with $10 \%$ sucrose (Leys \& Reiswig 1998) for $12 \mathrm{~h}$ at $4^{\circ} \mathrm{C}$. After rinsing in the same buffer, dehydration, and inclusion in Spurr's resin, ultrathin sections were prepared, stained with uranyl acetate and lead citrate, and observed with a TEM (JEOL 1010), implemented with a Bioscan system (Gatan) for image digitalization (Microscopy Unit of the Scientific and Technical Services of the University of Barcelona).

For scanning electron microscopy (SEM), samples were fixed in a cocktail $(6: 1)$ of a saturated solution of $\mathrm{HgCl}_{2}$ and $2 \%$ aqueous solution of $\mathrm{OsO}_{4}$ (Johnston \& Hildeman 1982), cryofractured in liquid $\mathrm{N}_{2}$, dehydrated, gold palladium metalized, and observed through a Hitachi S-3520N SEM (Microscopy Service ICM-CSIC, Barcelona).

For experiments in the laboratory, the target predators were the sea urchin Paracentrotus lividus and the fish Parablennius incognitus, which share habitat with $H$. columella. These 2 predators were collected in sufficient numbers from the sponge habitat

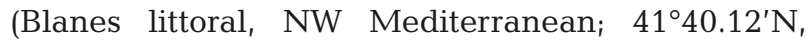
$2^{\circ} 47.10^{\prime} \mathrm{E}$ ), transported to the laboratory in seawater containers, and placed in an open-system aquarium at a similar temperature to that in their habitat $\left(22^{\circ} \mathrm{C}\right)$. All individuals were from the same size-class (adults), and no male livery was shown by any of them. They were starved for $7 \mathrm{~d}$ before experiments were initiated. Once the experiments were completed all individuals were taken back to their natural habitat.

\section{Chemical extraction}

Ca. $25 \mathrm{~g}$ of fresh sponges, corresponding to $40 \mathrm{ml}$ in volume (according to the water volume displaced when submerged in a measuring cylinder), were freeze-dried for $72 \mathrm{~h}$ and pounded. Acetone was used for chemical extraction because it has been reported to extract a wide range of secondary metabolites (Cimino et al. 1993). The extraction was done in an ultrasound bath for cell breaking and was performed in 2 steps. First, we added $20 \mathrm{ml}$ of acetone per gram of sponge powder, and the extraction lasted for $25 \mathrm{~min}$. Once the supernatant was removed, we added another $20 \mathrm{ml}$ of acetone per gram sponge and extracted it for $10 \mathrm{~min}$. The supernatants from the 2 extractions were pooled together in a previously weighed tube, and the solvent was totally evaporated in a hood. The tubes were weighed again after drying to determine the amount of crude extract obtained. The procedure was repeated 4 times (25 $\mathrm{g}$ of fresh sponge each time) and ended with a total crude extract of $72 \mathrm{mg}\left(0.45 \mathrm{mg} \mathrm{ml}^{-1}\right.$ sponge), which was preserved frozen in the darkness until the artificial food was prepared.

\section{Isolation of calcibacteria spherules}

The presence and abundance of calcibacteria in the sampled sponges (i.e. bacteria surrounded by a calcareous coat) were confirmed through optic and electron microscopes. The calcibacteria coats, which are calcium carbonate made according to X-diffraction analysis (Uriz et al. 2012), were obtained directly from fresh sponge samples. Ca. $25 \mathrm{~g}$ fresh sponge, $40 \mathrm{ml}$ in volume, were disaggregated and homogenized in sterile seawater to avoid dissolution of the calcite-made, calcibacteria spherules. The whole process of spherule isolation consisted of a series of centrifugations and re-suspensions (Fig. 1E,F) in an attempt to be as exhaustive as possible. Siliceous spicules precipitated first, forming part of the pellet after centrifugation, and were discarded.

The spicule-free homogenates were initially centrifuged at $200 \mathrm{rpm}$ for $1 \mathrm{~min}$ (Step 1), and the supernatants with the calcite spherules were removed and kept apart. The pellets, which still contained spherules, according to light microscope observation, were re- 

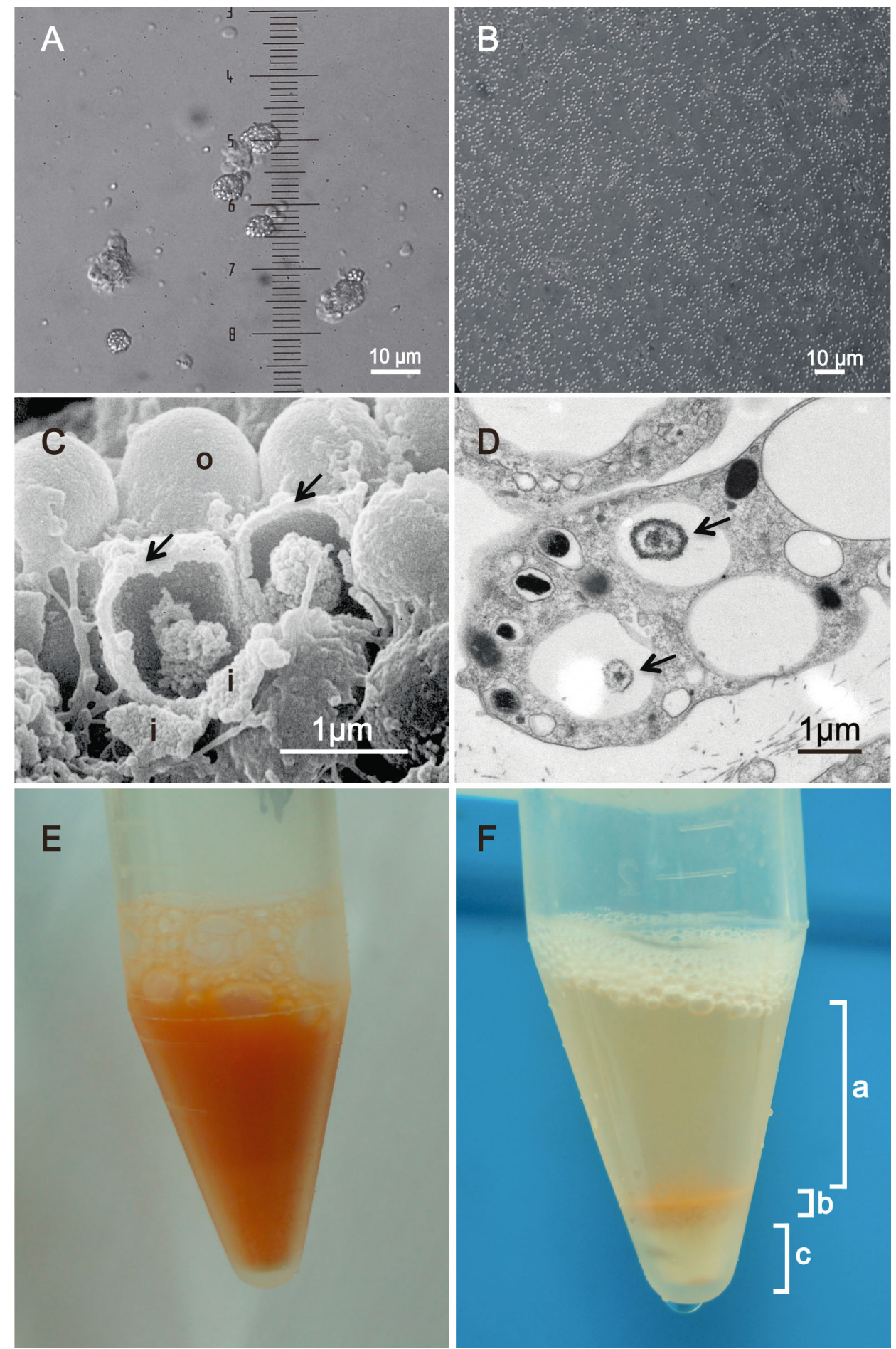

Fig. 1. Calcibacteria in (A-D) Hemmycale columella, and $(\mathrm{E}, \mathrm{F})$ the process of calcibacterial isolation. (A) Sponge cells (calcibacteriocytes) containing the calcified bacteria (which appear refringent through the light microscope). (B) Huge amounts of calcibacteria after cell dissociation of fresh sponges (light microscope). (C) Scanning electron microscope image of a cryofractured sponge showing entire and broken calcibacteria-i: internal side showing the nanospherules that form the calcite coat; o: outside of the calcite coat (arrows point to the zones where nanospherule arrangement in a layer is more conspicuous). (D) Transmission electron microscope image of a calcibacteriocyte containing 2 calcibacteria within their respective vacuoles (arrows); the calcareous envelope was dissolved during the fixation process by acidic fixators, i.e. glutaraldehyde). (E) Sponge homogenate after spicule removal: Step 1 of the cell dissociation and centrifugation process (see 'Materials and methods: Isolation of calcibacteria spherules'). (F) Step 2 of the process in which the debris of most sponge cells has already been removed - a: supernatant containing isolated calcibacteria in suspension; b: layer of calcibacteriocytes; c: settled calcibacteria 
suspended in $7 \mathrm{ml}$ of sterile seawater and centrifuged again at $500 \mathrm{rpm}$ for $2 \mathrm{~min}$ (Step 2). The resultant supernatants were removed and set apart. The upper layer of the pellet, which contained entire calcibacteriocytes, was also removed with a pipette, and resuspended with RIPA buffer (Sigma) and sterile seawater (1:1) to lyse the calcibacteriocytes; this was centrifuged at $500 \mathrm{rpm}$ for $2 \mathrm{~min}$ (Step 3). The various supernatants containing spherules were pooled together and centrifuged at $2000 \mathrm{rpm}$ for $4 \mathrm{~min}$ in order to precipitate the calcibacteria spherules (Step 4). The spherule-free supernatant (verified through light microscopy) was discarded, and finally the pellet was re-suspended in $1 \mathrm{ml}$ of sterile seawater. The whole process was repeated 3 times totaling $48 \mathrm{ml}$ of calcite spherules, which represented a concentration of $0.4 \mathrm{ml}$ spherules $\mathrm{ml}^{-1}$ sponge.

\section{Artificial food preparation}

Two types of artificial food were prepared according to the feeding behavior of the target predators: $4 \%$ carragenate plates for sea urchins and bread pellets for fishes.

\section{Paracentrotus lividus}

The food controls were prepared by adding $120 \mathrm{~g}$ of the fresh alga Cystoseira mediterranea, which is part of the diet of $P$. lividus' (Verlaque \& Nédelec 1983, Verlaque 1984), to $120 \mathrm{ml}$ of $4 \%$ carragenate. To detect any deterrent effect of the solvent used in the chemical treatment, acetone controls were also prepared by adding $12 \mathrm{ml}$ of acetone to $120 \mathrm{ml}$ of a $4 \%$ carragenate-alga mixture (i.e. $2.25 \mathrm{ml}$ of acetone per carragenate plate). Either the sponge crude extract (chemical treatment) or the calcibacterial treatments were added to $120 \mathrm{ml}$ of slightly warm $4 \%$ carragenate seawater-alga mix.

For the chemical treatment, we re-dissolved ca. $5.3 \mathrm{mg}$ of crude extract in $12 \mathrm{ml}$ of acetone and added this solution to the $120 \mathrm{ml}$ of $4 \%$ carragenate-alga mix, which approximately mimicked the crude volumetric concentration in the sponge (ca. $0.45 \mathrm{ml}$ of crude extract per milliliter of carragenate).

For the calcibacterial treatment, we added $48 \mathrm{ml}$ of the concentrated spherule suspension to $120 \mathrm{ml}$ of a $4 \%$ carragenate-alga mix, which approached the calcibacterial density estimated in fresh sponges ( $0.4 \mathrm{ml}$ of spherules per milliliter of carragenate). A total of $15 \mathrm{ml}$ of the carragenate-alga mix containing either the crude extract or the calcibacterial blend was poured into 8 Petri dishes (6 plates for experimental trials and 2 as hydration controls). The treatment combining the crude extract and the calcibacteria was prepared by adding both $5.3 \mathrm{mg}$ of sponge crude extract and $48 \mathrm{ml}$ of concentrated calcibacterial suspension to the carragenate-alga mix. After cooling, the plates were removed from the Petri dishes and weighed immediately before being offered to the sea urchins. Two plates per treatment were kept in aquaria free of sea urchins to estimate the possible weight gains because of carragenate hydration.

\section{Parablennius incognitus}

Hundreds of ca. $3 \mathrm{~mm}$ long, $1 \mathrm{~mm}$ thick pellets - an appropriate size considering the mouth size of the target fish - were hand made from smashed bread. Either the sponge crude extract solution or the spherule suspension was added in appropriated volumes to bread pellets to obtain ecologically relevant concentrations (i.e. similar to those present in the sponge tissues). The treatments considered for $P$. incognitus were: sponge crude extract (chemical treatment), calcibacteria spherules, and acetone control. The chemical treatment was prepared by adding ca. $4 \mathrm{mg}$ of crude extract, dissolved in $12 \mathrm{ml}$ acetone, to $10 \mathrm{~g}$ (ca. $40 \mathrm{ml}$ of bread pellets, measured in a measuring cylinder) to obtain a concentration of ca. $0.45 \mathrm{mg}$ of crude extract per milliliter of bread pellets.

The spherule treatment was prepared as described above by adding $16 \mathrm{ml}$ of spherules, suspended in $1 \mathrm{ml}$ of seawater, to $10 \mathrm{~g}$, ca. $40 \mathrm{ml}$, of bread pellets (resulting in a concentration of ca. $0.4 \mathrm{ml}$ of spherules per milliliter of pellets). The acetone control was prepared by adding $12 \mathrm{ml}$ of acetone to $10 \mathrm{~g}(40 \mathrm{ml})$ of bread pellets. The pellets containing the treatments were then air dried to facilitate manipulation. In the previous experiment on sea urchins no differences were found between the carragenate and acetone controls, so we only considered the acetone control in subsequent experiments.

\section{In situ sympatric fish assemblage}

The artificial food for the in situ experiment with the sympatric fishes at the sponge habitat was similar to that prepared for the fish experiment in the laboratory (see above) but the pellet size was larger (4 mm long and 1 to $2 \mathrm{~mm}$ thick) in order to adapt the food to the mouth size of the fishes targeted. We per- 
formed the same 3 treatments (crude extract, calcibacteria spherules, and acetone control) as in the $P$. incognitus experiment. Treatments were offered to the fish assemblage at random. Fishes at sea were adapted to feed on artificial food offered by divers for $7 \mathrm{~d}$ prior to the experiment.

\section{$P$. lividus experiment}

The sea urchins were starved for $1 \mathrm{wk}$ and then placed in individual 51 aquaria, with continuous aeration at $22^{\circ} \mathrm{C}$. Three treatments consisting of (1) the sponge crude extract, (2) the calcibacteria spherules, and (3) both components combined were offered. We used a total of 30 individuals, 6 per treatment (including controls). Two other aquaria were disposed under the above conditions to sink 2 plates of each treatment to assess their increase in weight due to hydration during the experiment. The plates were randomly distributed between individuals, and the experiment lasted for $48 \mathrm{~h}$. The plates were then recovered, slightly toweled, and weighed to calculate weight losses that were due to sea urchin grazing, after discounting the mean increase in weight of plates used to control hydration.

\section{P. incognitus experiment}

After 1 wk of adaptation to aquarium conditions, each $P$. incognitus individual was placed in a 51 aquarium $(\mathrm{N}=14)$ with continuous water flow at a constant temperature $\left(22^{\circ} \mathrm{C}\right)$. The experiment lasted for $8 \mathrm{~d}$. Every $2 \mathrm{~d}$ we offered 10 pellets of each treatment (crude extract, spherules, and acetone control) in random order to 4 randomly selected fishes, and recorded the number of pellets eaten or rejected per treatment. No pellet was ignored when offered to fish in this experiment. At the end, we had a total of 16 replicates per treatment. Those fishes that were not involved in a given trial were fed daily ad libitum with Sera ${ }^{\circledR}$ marine granulate.

\section{Sympatric fish experiment}

The field experiment was carried out in the Blanes sublittoral zone (NW Mediterranean; $41^{\circ} 40.12^{\prime} \mathrm{N}$, $2^{\circ} 47.10^{\prime} \mathrm{E}$ ), in summer 2013, on a rocky, 10 to $15 \mathrm{~m}$ deep, bottom. The most frequent fish species cooccurring in the sponge habitat were Chromis chromis, Diplodus vulgaris, Oblada melanura, and
Coris julis. Thus, we recorded the behavior of these 4 fishes with respect to the food offered. The number of fish participating in the experiment, as estimated from the number of pellets that they ate or rejected, was $>20$ per species (see Table 3 ), although we were unable to ensure that a given individual participated only once in the experiment.

The artificial food was taken to sea in large plastic syringes ( 1 treatment $^{-1}$ ) as described by Becerro et al. (2003). Treatments and controls (5 pellets treatment $^{-1}$ ) were randomly offered to fishes by slowly releasing the pellets into the water. Two independent SCUBA divers recorded the number of eaten or rejected pellets. A pellet was considered rejected by a fish if tried and spat out 3 or more times. When a pellet was ignored, or tried by a fish just once or twice and spat out and ignored, the outcome was annulled and a new pellet of the same treatment was offered later.

\section{Comparative deterrence quantification}

A deterrence index (Becerro et al. 2003) was used for comparing sea urchin and fish deterrence in the 3 experiments. The index (DET) was defined as:

$$
\mathrm{DET}=\frac{\frac{\mathrm{EC}}{\mathrm{OC}}-\frac{\mathrm{ET}}{\mathrm{OT}}}{\frac{\mathrm{EC}}{\mathrm{OC}}}
$$

where $\mathrm{EC}$ is either the number of control pellets eaten by fishes or the weight losses in the control agar plates offered to sea urchins and OC is the number of control pellets offered or the initial weight of the control plate; ET is the number of treatment pellets eaten or the decrease in weight of a treatment plate and OT is the number of treatment pellets offered or the initial weight of a give treatment plate. DET varies from 0 (no deterrence) to 1 (total deterrence).

\section{Statistical analyses}

Data from the experiments in the laboratory on the sea urchin $P$. lividus and the fish $P$. incognitus were analyzed by 1-way ANOVA after rank transformation, since they did not meet the assumptions for parametric analyses. The significance values of the post hoc pairwise comparisons (Newman-Keuls test) were adjusted by the false discovery rate (FDR) correction for multiple comparisons (Yekutieli \& Benjamini 1999).

Data from the sea experiment were analyzed using log-linear models for contingency tables. We tabu- 
lated our data with treatment (control and treated food), fish species tested, and consumption (eaten or rejected) as factors, and the number of occurrences (pellets) in each category as observed cell frequencies (Sokal \& Rohlf 1995). The statistical significance of the deviations of the observed frequencies from the expected frequencies was evaluated by Pearson's chi-squared. Statistical analyses were performed with Statistica 6 software.

\section{RESULTS}

\section{Calcibacterial presence/abundance}

Calcibacteria were present in the Hemimycale columella sponges used for the experiments, as proved by light and electron microscope observations. Calcibacteria spherules were extraordinarily abundant (Fig. 1A-D) in the sponge homogenates either free in suspension (due to their small size $[<1 \mu \mathrm{m}$ in diameter] and low weight) as a result of calcibacteriocyte damage or on the upper layer of the pellets within denser entire calcibacteriocytes. SEM pictures of cryofractured sponge tissue showed calcibacteria with a $100 \mathrm{~nm}$ coat of nanospherules arranged in a layer and with inner material corresponding to the bacteria (Fig. 1C). Images of intracellular bacteria deprived of the calcareous coat (likely due to calcium carbonate dissolution during the $\mathrm{pH}$-lowering fixation process) were obtained by TEM. The intracellular vacuoles maintained the size and shape of the calcibacterial coat (Fig. 1D).

\section{P. lividus experiment}

ANOVA results on ranks showed a significant effect $(p<0.001)$ of treatments on ingested food (Table 1). Post hoc comparisons (Newman-Keuls test) after FDR correction proved significant $(p<0.001)$ differences between the 3 treatments and the 2 con-

Table 1. One-way ANOVA on the deterrent effect of several treatments (carragenate control, acetone control, crude extract, calcibacteria spherules, and chemical and bacterial components combined) on the sea urchin Paracentrotus lividus

\begin{tabular}{|lccccc|}
\hline Effect & SS & df & MS & $F$ & $p$ \\
\hline Treatment & 1653.00 & 4 & 413.25 & 17.37 & $<0.001$ \\
Error & 594.50 & 25 & 23.78 & & \\
\hline
\end{tabular}

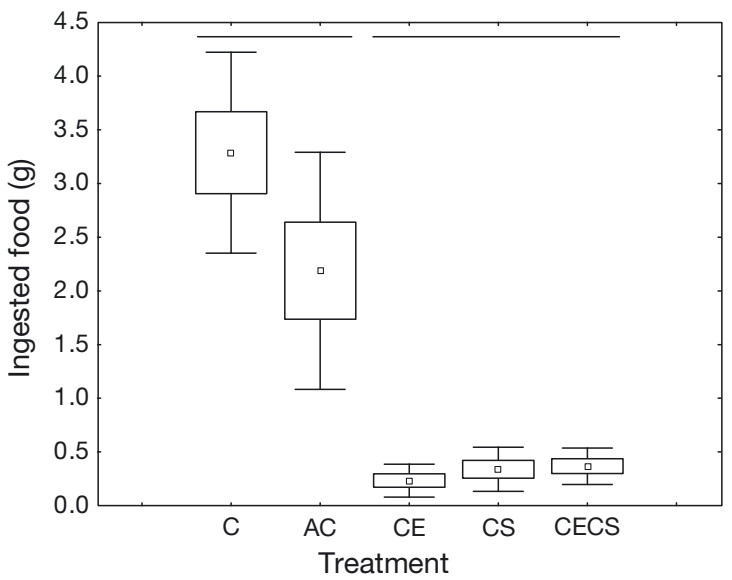

Fig. 2. Deterrent effect of treatments assayed on the sea urchin Paracentrotus lividus $(\mathrm{N}=6$; C: carragenate control; $\mathrm{AC}$ : acetone control, $\mathrm{CE}$ : sponge crude extract; CS: calcibacteria spherules; CECS: crude extract+calcibacteria). Horizontal bars at the top of the panel indicate no significant differences between treatments after false discovery rate correction $(\mathrm{p}<0.021)$

trols (carragenate control and acetone control), which were eaten similarly $(p=0.22)$. There were no significant differences in feeding between the calcibacteria spherules and the chemical treatment $(\mathrm{p}=$ 0.29 ), or between the chemical treatment and the chemical+calcibacteria spherule treatment $(p=0.29$; Fig. 2). Thus, the crude extract, the calcibacteria spherules, and the calcibacteria+crude extract similarly deterred sea urchins from feeding on $H$. columella, but the latter combination did not deter the sea urchin in an additive or synergetic way.

\section{P. incognitus experiment}

ANOVA on the number of pellets ingested by $P$. incognitus showed significant differences among treatments and the control (Newman-Keuls test, p < 0.001; Table 2). Post hoc multiple comparisons after FDR correction showed significant differences $(p<$ 0.001) between the calcibacterial treatment and the control but not ( $p=0.13)$ between the chemical treatment and the control (Fig. 3). Thus, only the

Table 2. One-way ANOVA on the deterrent effect of several treatments (control, crude extract, and calcibacteria spherules) on the fish Parablenius incognitus

\begin{tabular}{|lccccc|}
\hline Effect & SS & df & MS & $F$ & $p$ \\
\hline Treatment & 3548.49 & 2 & $\begin{array}{c}1774.25 \\
69.59\end{array}$ & 25.49 & $<0.001$ \\
Error & 2853.01 & 41 & 69.59 & \\
\hline
\end{tabular}




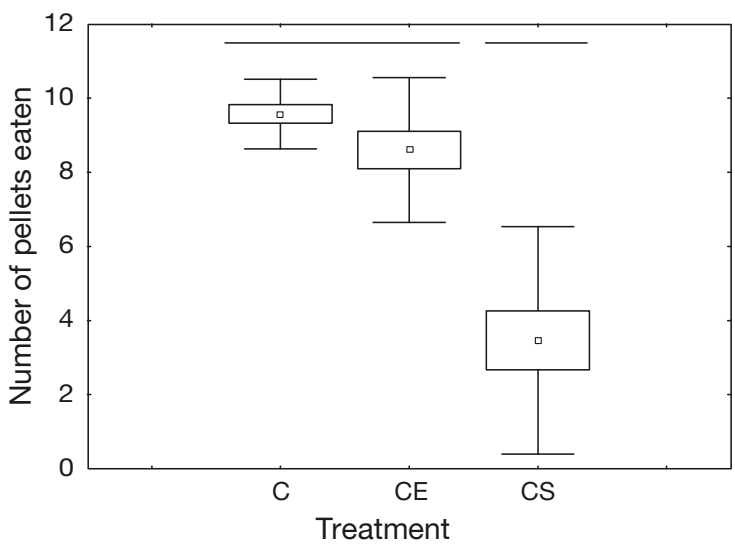

Fig. 3. Deterrent effects of treatments assayed on the fish Parablennius incognitus $(\mathrm{N}=16$; $\mathrm{C}$ : control; $\mathrm{CE}$ : sponge crude extract; CS: calcibacteria spherules). Horizontal bars indicate no significant differences between treatments after false discovery rate correction $(p<0.023)$. Boxes represent $\pm \mathrm{SE}$, bars $\pm \mathrm{SD}$

spherules of the symbiotic calcibacteria defended $H$. columella against predation by the small sympatric fish $P$. incognitus.

\section{Sympatric fish experiment}

The 3-way log-linear model for the contingency table with treatment, fish species, and ingested food as factors indicated that the assayed fish species, which shared habitat with the target sponge, were differently deterred from feeding by the 2 treatments assayed (Table $3 ; \chi^{2}, \mathrm{p}<0.001$ ). There were high significant differences $(\mathrm{p}<0.001)$ between the calcibacterial treatment and the control for the 4 sympatric fishes. Conversely, the chemical (crude extract) treatment was eaten sig-

Table 3. Frequency table from the in situ sympatric fish assemblage experiment that was used for contingency table analysis (143 pellets were offered per treatment). Asterisks indicate deterrent effect on ingestion $\left(\chi^{2},{ }^{*} p<0.05 ;{ }^{* *} p<0.01 ;{ }^{\text {ns }}\right.$ : non-significant)

\begin{tabular}{|lccccc|}
\hline Ingested pellets & $\begin{array}{c}\text { Chromis } \\
\text { chromis }\end{array}$ & $\begin{array}{c}\text { Oblada } \\
\text { melanura }\end{array}$ & $\begin{array}{c}\text { Diplodus } \\
\text { vulgaris }\end{array}$ & $\begin{array}{c}\text { Coris } \\
\text { julis }\end{array}$ & Total \\
\hline $\begin{array}{l}\text { Acetone control } \\
\text { Yes }\end{array}$ & 31 & 33 & 27 & 40 & 131 \\
No & 4 & 6 & 1 & 0 & 11 \\
Crude extract & & & & & \\
Yes & 23 & 0 & 17 & 43 & 83 \\
No & $22^{\text {ns }}$ & $24^{* *}$ & $14^{* *}$ & $0^{\text {ns }}$ & 60 \\
Calcibacteria spherules & & & & \\
Yes & 0 & & 4 & 35 & 39 \\
No & $38^{* *}$ & $42^{* *}$ & $18^{* *}$ & $7^{*}$ & 105 \\
Total & 118 & 105 & 81 & 125 & 429 \\
\hline
\end{tabular}

nificantly less often than the control for 2 out of the 4 assayed fishes (Table $3 ; \chi^{2}, \mathrm{p}<0.001$ ).

\section{Comparative deterrence quantification}

The deterrence index (DET), which represents the relation between the consumed food and the food offered in treatments and controls, varied between treatments and among species (Fig. 4). It approached 1 for both the chemical and the calcibacterial treatments in Paracentrotus lividus, while it significantly varied between the calcibacterial $(\mathrm{DET}=0.64)$ and chemical (DET $=0.1$ ) treatments for $P$. incognitus.

The fish deterred most by the 2 treatments (DET $=$ 1 , crude extract and calcibacteria spherules) was the sparid Oblada melanura. Conversely, the labrid Coris julis, the pomacentrid Chromis chromis, and the sparid Diplodus vulgaris showed significantly lower deterrence indices for the chemical treatment than for the calcibacterial treatment $(\mathrm{DET}=0, \mathrm{DET}=$ 0.4, and DET $=0.4$, respectively) (Fig. 4).

\section{DISCUSSION}

The various deterrence experiments performed revealed that the sponge Hemimycale columella combines $>1$ defense mechanism to dissuade potential predators. Some predators are deterred by both secondary metabolites and calcibacteria-a case example of the evolutionary fixation of redundant mechanisms of defense in a species to widen the spectrum of predators deterred. On the other hand,

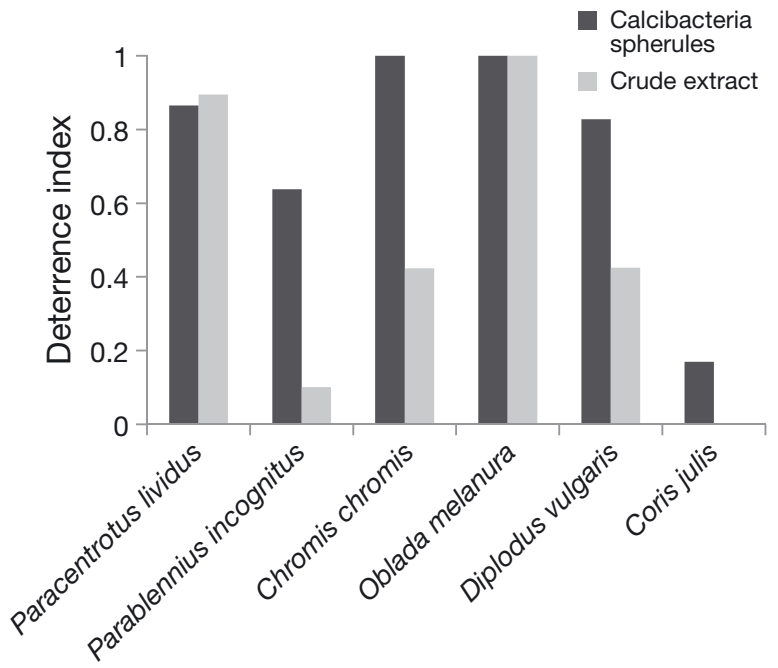

Fig. 4. Deterrence index of sponge crude extract and calcibacteria spherules for several species assayed 
sponges are not the only organisms to present 2 different types of defenses; crude extracts and sclerites have also been reported to exert anti-predatory functions in gorgonians (van Alstyne \& Paul 1992).

The spherules produced by the symbiotic calcibacteria significantly deterred all species assayed; thus they appear to represent a generalist defense mechanism. Conversely, the chemical extract of $\mathrm{H}$. Columella deterred some of the species assayed, but not others; thus it seems to represent a more speciesspecific defense mechanism.

The sea urchin Paracentrotus lividus was deterred from feeding on $H$. columella by both the sponge's chemical extracts and the calcibacteria spherules, as well as by a combination of both components; this finding agrees well with the observed lack of predation of $P$. lividus on $H$. columella in the field (L. Garate, A. Blanquer, M.-J. Uriz pers. obs.). Several studies reported that some sponge components deterred this sea urchin, but the outcome of the assays performed here varied as a function of the sponge species, the types of defense analyzed, and the sea urchin species used. Sponge spicules, spongin, collagen, or calcium carbonate may deter some sea urchins from predation (Pennings \& Svedberg 1993, Uriz et al. 1996). Conversely, other sea urchin species feed on sponges habitually, despite the presence of siliceous spicules (De Ridder \& Lawrence 1982, Santos et al. 2002). These contrasting results illustrate predator-dependent outcomes to the same type of defense.

$P$. lividus has been reported to feed on sponge species devoid of spicules when food resources are limited (Boudouresque \& Verlaque 2007). Since $H$. columella shows a relatively poor spicule complement, predation by $P$. lividus on this sponge species would be expected, but has not been observed. Our results showed that the calcium carbonate spherules of the symbiotic calcibacteria at natural concentrations deter this sea urchin. The spherules may be unpalatable to sea urchins, but not strictly toxic (Birenheide et al. 1993), and, likely, their high concentration in sponge tissues may decrease sponge nutritional quality; thus, field sea urchins may select other more attractive food sources for optimal growth. Moreover, it has been reported that both calcite and aragonite deter some herbivore fishes from feeding (Pennings \& Svedberg 1993), which has been related to a decrease in fish gut $\mathrm{pH}$ impairing food digestion (Schupp \& Paul 1994).

Besides the symbiotic calcibacteria, $H$. columella produces secondary metabolites with demonstrated antimitotic, cytotoxic, and antibacterial activity (Amade et al. 1987, Uriz et al. 1992, Becerro et al. 1997a). Here we report on another defensive function of these secondary metabolites since they discourage the sea urchin $P$. lividus from grazing. It has also been reported that $P$. lividus is deterred by the crude extract of the sponge Crambe crambe (Uriz et al. 1996, Becerro et al. 1997b) and the seagrass Posidonia oceanica (Vergés et al. 2007), while it appears to consume the alga Caulerpa taxifolia during the months when it presents the lowest amount of secondary metabolites (Lemee et al. 1996). Protection from the devastating grazing by sea urchins (Guidetti \& Dulčić 2007) seems to be widespread among many benthic organisms, which have developed deterrent toxicants.

The outcomes of the fish experiments differed according to the fish species assayed. In general, calcareous spherules deterred fishes more efficiently than sponge crude extract did, but, for some species, both components were similarly deterrent. Previous studies reported that sponge skeletal structures are deterrents for fishes (Burns \& Ilan 2003, Jones et al. 2005, but see Chanas \& Pawlik 1995, 1996). H. columella is a spicule-poor species, and the high concentration of calcibacteria spherules at the sponge periphery may replace spicules as deterrent elements for fishes.

The indexes formulated to compare the deterrence intensity among the potential predators assayed (DET) varied across species depending on the treatment. The calcibacteria DET index showed the highest value for C. chromis and O. melanura, followed by the sea urchin P. lividus (DET = 1), and exerted the lowest effect $(\mathrm{DET}=0.19)$ on $C$. julis. Such differences may be due to differences in the habitual prey preferentially targeted in the field by each predator. Thus, fishes such as C. julis, which usually feed on invertebrates provided with an external skeleton, such as mollusks, gastropods, bivalves, and crustaceans (Kabasakal 2001, Stergiou \& Karpouzi 2002), may be more adapted to encountering calcareous structures in their diet.

The DET index for the chemical treatment varied drastically with the predator species: while it reached its highest value for the sea urchin P. lividus and the fish Oblada melanura, and a medium value for $D$. vulgaris and C. chromis, it was close to zero for $P$. incognitus and $C$. julis.

The contrasting deterrent effects found for the crude extract may also be related to differences in the natural feeding habits of the species assayed. $O$. melanura and $D$. vulgaris are considered opportunistic predators that feed on an array of both benthic and pelagic organisms (Pallaoro et al. 2003, 2006). 
Thus, they may select other, non-toxic food sources in the field. The small bleniid fish ( $P$. incognitus) captures small benthic animals in the field, while grazing the surface of rocky substrata and encrusting invertebrates (Goldschmid \& Kotrschal 1981); thus, it might be adapted to ingest small amounts of potentially toxic species such as $H$. columella and $C$. crambe (Becerro et al. 1997b) while capturing small invertebrates dwelling on sponges. The labrid $C$. julis is a voracious species that has been reported to predate on crustaceans and gastropod mollusks (Fasola et al. 1997, Kabasakal 2001); apparently it also tolerates, to some extent, the bioactive compounds produced by the alga Caulerpa prolifera (Sureda et al. 2006). Thus, the 2 latter fishes seem to show some resistance to the secondary metabolites of benthic invertebrates. On the other hand, pomacentrid fishes such as C. chromis are also opportunistic, omnivorous species that include sponges in their diet (Emery 1973, Emery \& Thresher 1980, Horn 1989). C. chromis, however, has been reported to avoid artificial food containing the crude extract of the nudibranch Discodoris indecora, which obtains its metabolites from Ircinia spp. sponges (Marin et al. 1997).

Reinforcing the invertebrate periphery by mineral materials in order to make it less attractive to potential predators is the main function of mineral exoskeletons (Uriz 2006). Sponges concentrate microscleres at the periphery to form a mineral cortex (Uriz et al. 2003). Rohde \& Schupp (2011) reported a higher deterrent effect of artificial food containing siliceous spicules from the sponge cortex than from the choanosome. This is likely related to the spicule sizes and may depend on the mouth size of the predator considered. Small spicules (microscleres) are densely packed in the sponge cortex (Boury-Esnault \& Rützler 1997), and thus more likely to deter small predators, while protruding choanosomal megascleres (from hundreds of micrometers to millimeters) likely deter larger mouthed predators (Uriz et al. 2003). The calcified calcibacteria of $H$. columella are spherules of ca. $1 \mu \mathrm{m}$ size that are transported by amoeboid cells (calcibacteriocytes) to the sponge sub-ectosomal zone (Uriz et al. 2012) where they form a kind of calcareous cortex. Since these calcareous spherules appear to be so efficient in deterring the potential predators assayed, their high concentration at the sponge periphery may make them very efficient in deterring an array of small-mouthed predators.

Although chemical extracts and calcibacteria deterred some potential predators individually, the deterrent effect did not increase in additive or synergistic ways when they were combined in a treatment. The few studies in which the possible synergism between structural defenses and crude extracts from sponges has been considered showed disparate results (e.g. Hay et al. 1994, Burns \& Ilan 2003, Hill et al. 2005, Jones et al. 2005, Ribeiro et al. 2012).

The Hemimycale-calcibacteria symbiosis is not the only case in which a bacterium protects a sponge from predation. Recently, a symbiotic beta-proteobacteria of the sponge C. crambe has been reported to participate in the metabolic pathways (Croué et al. 2013) of 2 highly deterrent metabolites of C. crambe (Uriz et al. 1996). On the other hand, polyketide synthethases (PKS) of bacterial origin, with bioactive functions, have been found in many sponge-bacteria symbioses (Piel et al. 2004, Haber et al. 2011, Esteves et al. 2013). In all cases, the resulting substances produced by symbiotic microorganisms, either secondary metabolites or carbonate spherules, may be used by sponge species to their own benefit (deterrent, antibacterial, or antifouling roles; Uriz et al. 1996), thus promoting the persistence of sponge-bacteria associations.

Since the concentrations (at a volumetric proportion) of chemicals and calcibacteria used in the experiments were roughly similar to those found in natural sponges, we are confident that protection from predation is one of the benefits that $H$. columella receives from its symbiosis with calcibacteria. Its contribution to sponge survival may have helped establish this unique symbiosis between marine sponges and calcifying bacteria. However, the sponge's secondary metabolites also exert a deterrent effect against some potential sponge predators. The calcibacteria and crude extracts together do not seem to have an additive or synergetic effect on potential sponge predators, but rather may be engaged in enlarging the array of potential predators deterred. The chemical defenses of $H$. columella contribute to the complexity of Mediterranean species interactions, which supports the theory of Buss (1976), which was recently substantiated by Loh \& Pawlik (2014) for sponge communities of coral reefs. In contrast, symbiotic calcibacteria unambiguously contribute to protect the sponge from generalist predators and thus favor the species' success. This is the first time that a physical defense produced by symbiotic bacteria has been documented.

Acknowledgements. We thank Jan Sureda for help with the field experiments and A. Lloveras and G. Agell for help with the laboratory assays. This study (M.J.U.) has partially been funded by the projects MarSymbiomics (MINECO, I+D+I of Excellence, CTM2013-43287-P), the Benthic Ecology Consolidate Team of the Generalitat de Catalunya (2014 SGR-120), and BluePharm Train FP7 People-INT (Ref. 2013- 
667786). All experiments complied with institutional, national, and international ethics guidelines concerning the use of animals in research. None of the species used were listed as 'Endangered'.

\section{LITERATURE CITED}

Amade P, Charroin C, Baby C, Vacelet J (1987) Antimicrobial activities of marine sponges from the Mediterranean Sea. Mar Biol 94:271-275

Arias J, Santos-Acevedo M, Newmark-Umbreit F (2011) Evaluación del potencial antidepredador de los extractos orgánicos crudos de quince esponjas marinas. Bol Investig Mar Costeras 40:293-308

> Becerro MA, Lopez NI, Turon X, Uriz MJ (1994) Antimicrobial activity and surface bacterial film in marine sponges. J Exp Mar Biol Ecol 179:195-205

> Becerro MA, Turon X, Uriz MJ (1997a) Multiple functions for secondary metabolites in encrusting marine invertebrates. J Chem Ecol 23:1527-1547

> Becerro MA, Uriz MJ, Turon X (1997b) Chemically-mediated interactions in benthic organisms: the chemical ecology of Crambe crambe (Porifera, Poecilosclerida). Hydrobiologia 355:77-89

> Becerro MA, Thacker RW, Turon X, Uriz MJ, Paul VJ (2003) Biogeography of sponge chemical ecology: comparisons of tropical and temperate defenses. Oecologia 135:91-101

Bertolino M, Cerrano C, Bavestrello G, Carella M, Pansini M, Calcinai B (2013) Diversity of Porifera in the Mediterranean coralligenous accretions, with description of a new species. ZooKeys 336:1-37

> Birenheide R, Amemiya S, Motokawa T (1993) Penetration and storage of sponge spicules in tissues and coelom of spongivorous echinoids. Mar Biol 115:677-683

Blanquer A, Uriz MJ, Galand PE (2013) Removing environmental sources of variation to gain insight on symbionts vs. transient microbes in high and low microbial abundance sponges. Environ Microbiol 15:3008-3019

Blunt JW, Copp BR, Hu WP, Munro MH, Northcote PT, Prinsep MR (2009) Marine natural products. Nat Prod Rep 26: $170-244$

Boudouresque CF, Verlaque M (2007) Ecology of Paracentrotus lividus. Dev Aquacult Fish Sci 37:243-285

Boury-Esnault N, Rützler K (eds) (1997) Thesaurus of sponge morphology. Smithson Contrib Zool 596:1-55

Burns E, Ilan M (2003) Comparison of anti-predatory defenses of Red Sea and Caribbean sponges. II. Physical defense. Mar Ecol Prog Ser 252:115-123

Buss LW (1976) Better living through chemistry: the relationship between allelochemical interactions and competitive networks. In: Harrison FW, Cowden RR (eds) Aspects of sponge biology. Academic Press, New York, NY, p 315-327

> Chanas B, Pawlik JR (1995) Defenses of Caribbean sponges against predatory reef fish. II. Spicules, tissue toughness, and nutritional quality. Mar Ecol Prog Ser 127:195-211

> Chanas B, Pawlik JR (1996) Does the skeleton of a sponge provide a defense against predatory reef fish? Oecologia 107:225-231

> Chesson PL (2000) Mechanisms of maintenance of species diversity. Annu Rev Ecol Syst 31:343-366

> Chesson PL, Warner RR (1981) Environmental variability promotes coexistence in lottery competitive systems. Am Nat 117:923-943
Cimino G, Crispino A, Madaio A, Trivellone E, Uriz MJ (1993) Raspacionina B, a further triterpenoid from the Mediterranean sponge Raspacionina aculeata. J Nat Prod 56:534-538

> Croué J, West NJ, Escande ML, Intertaglia L, Lebaron P, Suzuki MT (2013) A single betaproteobacterium dominates the microbial community of the crambescidinecontaining sponge Crambe crambe. Sci Rep 3:2583

> De Caralt S, Bry D, Bontemps N, Turon X, Uriz MJ, Banaigs B (2013) Sources of secondary metabolite variation in Dysidea avara (Porifera: Demospongiae): the importance of having good neighbors. Mar Drugs 11:489-503

De Ridder C, Lawrence JM (1982) Food and feeding mechanisms: Echinoidea. In: Jangoux M, Lawrence JM (eds) Echinoderm nutrition. AA Balkema, Rotterdam, p 55-116

Emery AR (1973) Comparative ecology and functional osteology of fourteen species of damselfish (Pisces: Pomacentridae) at Alligator Reef, Florida Keys. Bull Mar Sci 23:649-770

Emery AR, Thresher RE (1980) Biology of the damselfishes. Bull Mar Sci 30:145-328

Esteves AI, Hardoim CC, Xavier JR, Gonçalves J, Costa R (2013) Molecular richness and biotechnological potential of bacteria cultured from Irciniidae sponges in the northeast Atlantic. FEMS Microbiol Ecol 85:519-536

Fasola M, Canova L, Foschi F, Novelli O, Bressan M (1997) Resource use by a Mediterranean rocky slope fish assemblage. Mar Ecol (Berl) 18:51-66

Goldschmid A, Kotrschal K (1981) Feeding ecology of three populations of Blennius incognitus Bath, 1968 (Pisces: Teleostei: Blenniidae) during the reproductive period and under human influence. Mar Ecol (Berl) 2:1-14

Guidetti P, Dul i J (2007) Relationships among predatory fish, sea urchins and barrens in Mediterranean rocky reefs across a latitudinal gradient. Mar Environ Res 63: 168-184

Haber M, Carbone M, Mollo E, Gavagnin M, Ilan M (2011) Chemical defense against predators and bacterial fouling in the Mediterranean sponges Axinella polypoides and A. verrucosa. Mar Ecol Prog Ser 422:113-122

Hardoim CCP, Costa R (2014) Microbial communities and bioactive compounds in marine sponges of the family Irciniidae-a review. Mar Drugs 12:5089-5122

Hay ME, Kappel QE, Fenical W (1994) Synergisms in plant defenses against herbivores: interactions of chemistry, calcification, and plant quality. Ecology 75:1714-1726

Hill MS, Lopez NA, Young KA (2005) Anti-predator defenses in western North Atlantic sponges with evidence of enhanced defense through interactions between spicules and chemicals. Mar Ecol Prog Ser 291:93-102

Horn MH (1989) Biology of marine herbivorous fishes. Oceanogr Mar Biol Annu Rev 27:167-272

Johnston IS, Hildeman WH (1982) Cellular organization in the marine demosponge Callyspongia diffusa. Mar Biol $67: 1-7$

> Jones AC, Blum JE, Pawlik JR (2005) Testing for defensive synergy in Caribbean sponges: bad taste or glass spicules? J Exp Mar Biol Ecol 322:67-81

Kabasakal H (2001) Description of the feeding morphology and the food habits of four sympatric labrids (Perciformes, Labridae) from south-eastern Aegean Sea, Turkey. Neth J Zool 51:439-455

Knowlton AL, Highsmith RC (2005) Nudibranch-sponge feeding dynamics: benefits of symbiont-containing sponge to Archidoris montereyensis (Cooper, 1862) and recovery 
of nudibranch feeding scars by Halichondria panicea (Pallas, 1766). J Exp Mar Biol Ecol 327:36-46

Lemee R, Boudouresque CF, Gobert J, Malestroit P, Mari X, Meinesz A, Ruitton S (1996) Feeding behaviour of Paracentrotus lividus in the presence of Caulerpa taxifolia introduced in the Mediterranean Sea. Oceanol Acta 19: 245-253

> Leon YM, Bjorndal KA (2002) Selective feeding in the hawksbill turtle, an important predator in coral reef ecosystems. Mar Ecol Prog Ser 245:249-258

Leys SP, Reiswig HM (1998) Transport pathways in theneotropical sponge Aplysina. Biol Bull 195:30-42

$>$ Loh TL, Pawlik JR (2014) Chemical defenses and resource trade-offs structure sponge communities on Caribbean coral reefs. Proc Natl Acad Sci USA 111:4151-4156

- Marin A, Belluga ML, Scognamiglio G, Cimino G (1997) Morphological and chemical camouflage of the Mediterranean nudibranch Discodoris indecora on the sponges Ircinia variabilis and Ircinia fasciculata. J Molluscan Stud 63:431-439

Martin D, Uriz MJ (1993) Chemical bioactivity of Mediterranean benthic organisms against embryos and larvae of marine invertebrates. J Exp Mar Biol Ecol 173:11-27

McClintock JB, Baker BJ, Slattery M, Hamann M, Kopitzke R, Heine J (1994) Chemotactic tube-foot responses of a spongivorous sea star Perknaster fuscus to organic extracts from antarctic sponges. J Chem Ecol 20:859-870

$>$ Monks NR, Lerner C, Henriques AT, Farias FM, Schapoval EE, Suyenaga ES, Mothes B (2002) Anticancer, antichemotactic and antimicrobial activities of marine sponges collected off the coast of Santa Catarina, southern Brazil. J Exp Mar Biol Ecol 281:1-12

Pallaoro A, Santic M, Jardas I (2003) Feeding habits of the saddled bream, Oblada melanura (Sparidae), in the Adriatic Sea. Cybium 27:261-268

Pallaoro A, Santic M, Jardas I (2006) Feeding habits of the common two-banded sea bream, Diplodus vulgaris (Sparidae), in the eastern Adriatic Sea. Cybium 30:19-25

Pennings SC, Svedberg JM (1993) Does $\mathrm{CaCO}_{3}$ in food deter feeding by sea urchins? Mar Ecol Prog Ser 101:163-167

> Piel J, Hui D, Wen G, Butzke D, Platzer M, Fusetani N, Matsunaga S (2004) Antitumor polyketide biosynthesis by an uncultivated bacterial symbiont of the marine sponge Theonella swinhoei. Proc Natl Acad Sci USA 101: 16222-16227

Ribeiro SM, Bianco ÉM, Rogers R, Teixeira VL, Pereira RC (2010) Chemical defense of Hymeniacidon heliophila (Porifera: Halichondrida) against tropical predators. Braz J Oceanogr 58:315-321

> Ribeiro SM, Cassiano KM, Cavalcanti DN, Teixeira VL, Pereira RC (2012) Isolated and synergistic effects of chemical and structural defenses of two species of Tethya (Porifera: Demospongiae). J Sea Res 68:57-62

Rohde S, Schupp PJ (2011) Allocation of chemical and structural defenses in the sponge Melophlus sarasinorum. J Exp Mar Biol Ecol 399:76-83

Santos CP, Coutinho AB, Hajdu E (2002) Spongivory by Eucidaris tribuloides from Salvador, Bahia (Echinodermata: Echinoidea). J Mar Biol Assoc UK 82:295-297

Schupp PJ, Paul VJ (1994) Calcification and secondary metabolites in tropical seaweeds: variable effects on herbivorous fishes. Ecology 75:1172-1185

Sipkema D, Franssen MCR, Osinga R, Tramper J, Wijffels RH (2005) Marine sponges as pharmacy. Mar Biotechnol $7: 142-162$

Editorial responsibility: Antonio Bode,

A Coruña, Spain
Sokal RR, Rohlf FJ (1995) Biometry. Freeman \& Co, New York, NY

Stergiou KI, Karpouzi VS (2002) Feeding habits and trophic levels of Mediterranean fish. Rev Fish Biol Fish 11: $217-254$

Sureda A, Box A, Enseñat M, Alou E, Tauler P, Deudero S, Pons A (2006) Enzymatic antioxidant response of a labrid fish (Coris julis) liver to environmental caulerpenyne. Comp Biochem Physiol C Toxicol Pharmacol 144:191-196

Taylor MW, Radax R, Steger D, Wagner M (2007) Spongeassociated microorganisms: evolution, ecology, and biotechnological potential. Microbiol Mol Biol Rev 71: 295-347

> Thacker RW, Freeman CJ (2012) Sponge-microbe symbioses: recent advances and new directions. Adv Mar Biol 62:57-111

- Thacker RW, Becerro MA, Lumbang WA, Paul VJ (1998) Allelopathic interactions between sponges on a tropical reef. Ecology 79:1740-1750

Uriz MJ (2006) Mineral skeletogenesis in sponges. Can J Zool 86:1-35

Uriz MJ, Martin D, Rosell D (1992) Relationships of biological and taxonomic characteristics to chemically mediated bioactivity in Mediterranean littoral sponges. Mar Biol 113:287-297

> Uriz MJ, Turon X, Becerro MA, Galera J (1996) Feeding deterrence in sponges. The role of toxicity, physical defenses, energetic contents, and life-history stage. J Exp Mar Biol Ecol 205:187-204

Uriz MJ, Turon X, Becerro MA, Agell G (2003) Siliceous spicules and skeleton frameworks in sponges: origin, diversity, ultrastructural patterns, and biological functions. Microsc Res Tech 62:279-299

> Uriz MJ, Agell G, Blanquer A, Turon X, Casamayor EO (2012) Endosymbiotic calcifying bacteria: a new cue to the origin of calcification in Metazoa? Evolution 66: 2993-2999

van Alstyne KL, Paul VJ (1992) Chemical and structural defenses in the sea fan Gorgonia ventalina: effects against generalist and specialist predators. Coral Reefs 11:155-159

Van Soest R (2002) Family Hymedesmiidae Topsent, 1928. In: Hooper JNA, Van Soest RWM (eds) Systema Porifera: a guide to the classification of sponges. Kluwer Academic/Plenum Publishers, New York, NY, p 575-601

Vergés A, Becerro MA, Alcoverro T, Romero J (2007) Experimental evidence of chemical deterrence against multiple herbivores in the seagrass Posidonia oceanica. Mar Ecol Prog Ser 343:107-114

Verlaque M (1984) Biologie des juveniles de l'oursin herbivore Paracentrotus lividus Lamarck: séléctivité du broutage et impact de l'éspece sur les communautés algales de substract rocheux en Corse (Méditerranée, France). Bot Mar 27:401-424

Verlaque M, Nédelec H (1983) Biologie de Paracentrotus lividus (Lamarck) sur substract rocheux en Corse (Méditerranée, France): alimentation des adultes. Vie Milieu 33:191-202

> Wulff JL (2000) Sponge predators may determine differences in sponge fauna between two sets of mangrove cays, Belize barrier reef. Atoll Res Bull 477:251-263

Yekutieli D, Benjamini Y (1999) Resampling-based false discovery rate controlling multiple test procedures for correlated test statistics. J Stat Plan Inference 82:171-196 